\title{
Adsorption Study for Removal of Mn (II) Ion in Aqueous Solution by Hydrated Ferric (III) Oxides
}

\author{
Somchintana Puttamat and Varong Pavarajarn
}

\begin{abstract}
In this study, adsorption characteristic of manganese (II) ion onto hydrated ferric (III) oxides (HFOs) nanoparticle resins was analyzed and fitted with adsorption isotherm models such as Freundlich, Langmuir, Temkin and Dubinin-Radushkevich isotherms. The Freundlich isotherm model gave the highest $\boldsymbol{R}^{2}$ value of 0.9739 . The fitted Freundlich parameter $(n)$ is 6.757 , which indicates favorable sorption. The heat of sorption process was estimated from Temkin isotherm model to be $96.749 \mathrm{~J} \cdot \mathrm{mol}^{-1}$ and the mean free energy was estimated from Dubinin-Radushkevich isotherm model to be 288.675 $\mathrm{J} \cdot \mathrm{mol}^{-1}$. The thermodynamic parameters were calculated and it was found that the adsorption process was spontaneous and endothermic and was favored at higher temperature.
\end{abstract}

Index Terms-Hydrated ferric (III) oxide (HFOs) nanoparticle, adsorption, equilibrium isotherm and manganese (II) ion.

\section{INTRODUCTION}

Manganese (Mn) is a heavy metal commonly found in soil, sediment and especially in ground water. Not only it has effect on appearance and taste of the water, it also causes health problems on neurological and muscle function in humans. The Department of Environment Services Health Risk Assessment Program has adopted the health based standard of manganese of $0.84 \mathrm{mg} \cdot \mathrm{L}^{-1}$.

Manganese can present in water in one of three basic forms i.e., dissolved, particulate and colloids, depending on $\mathrm{pH}$ of the solution. Nevertheless, the most common treatment techniques of manganese contaminated water is oxidation/filtration and adsorbing onto ion exchange resin [1]-[3].

Oxidation of the dissolved manganese creates particles of manganese dioxide $\left(\mathrm{MnO}_{2}\right)$. The oxidation treatment is more effective in removing high concentration of dissolved manganese than the ion exchange. However, dissolved manganese is generally oxidized so slowly that it takes relatively long time for precipitation, hence it hardly becomes cost effective. The oxidation with chlorine becomes more effective when the $\mathrm{pH}$ is greater than 9.5 [4], [5].

Ion exchange technique employing sodium chloride solution can remove low concentration of dissolved manganese when the $\mathrm{pH}$ is greater than 6.8. Nevertheless, a simple ion exchange process is only driven by electrostatic interaction and it is nonspecific for heavy metal removal. This

Manuscript received May 31, 2015; revised August 16, 2015. This work was a part of master degree thesis research at the Department of Chemical Engineering, Faculty of Engineering, Chulalongkorn University.

The authors are with the Department of Chemical Engineering, Faculty of Engineering, Chulalongkorn University, Thailand (e-mail: psomchin@tu.ac.th, varong.p@chula.ac.th). gives rise to the frequent regeneration and high operation cost, rendering ion exchange technology unattractive. The use of chemically stable polymeric chelating exchanger has resolved the problem technically, but it is often too expensive to justify the applications for heavy metals removal from water and wastewater [1]-[7].

The major aim of the present study is to explore the adsorption behavior of $\mathrm{Mn}^{2+}$ in single ion system. In particular, we evaluated the equilibrium adsorption data by adsorption isotherms i.e., Freundlich, Langmuir, Temkin and Dubinin-Radushkevich. Also, we intend to evaluate the use of HFOs-resin in removing $\mathrm{Mn}^{2+}$ from simulated wastewater.

\section{EXPERIMENTAL METHOD}

\section{A. Preparation of the HFOs-Resin}

Precipitated hydrated Fe(III) oxides or HFOs nanoparticle were prepared by using Kastel ${ }^{\circledR}$ C300L (Siam Machinery Thai Co., Ltd.), which is a commercially available macroporous cation exchange resin with polystyrene matrix and sulfonic acid functional group, as the parent cation exchanger. Size of the exchanger resin beads varied between 450 to $550 \mu \mathrm{m}$. The preparation of HFOs-resin was consisted of the following three steps [8]. Firstly, Fe(III) was loaded onto the sulfonic acid sites of the cation exchanged by passing $4 \% \mathrm{FeCl}_{3}$ (AR grade, Merck $\mathrm{KGaA}$ ) solution at an approximate $\mathrm{pH}$ of 2.0 through a column packed with the resin. Secondly, desorption of $\mathrm{Fe}$ (III) and simultaneous precipitation of $\mathrm{Fe}$ (III) hydroxides took place within the gel and pore phase of the exchanger through passage of a solution containing both $\mathrm{NaCl}$ (AR grade, Merck $\mathrm{KGaA}$ ) and $\mathrm{NaOH}$ (AR grade, Merck KGaA) solution, each at $5 \% \mathrm{w} / \mathrm{v}$ concentration, through the column. Finally, the column was rinsed and washed with a $50 \%$ ethanol (AR grade, Merck $\mathrm{KGaA}$ ), aqueous solution followed by a mild thermal treatment $(333 \mathrm{~K})$ for $6 \mathrm{~h}$ under $\mathrm{N}_{2}$ atmosphere. The obtained HFOs-resin was then kept in vacuum desiccator.

\section{B. The Determination of Bulk Density}

The bulk density of each of the sample of Kastel ${ }^{\circledR}$ cation exchange resins and HFOs-resin was determined using Archimedes's principle [9] by weighing $10 \mathrm{~mL}$ measuring cylinder before and after filling with the samples. The measuring cylinder was then dried and the sample was packed inside, leveled and weighed. The weight of the sample packed in the measuring cylinder was determined from the difference in weight of the filled and empty measuring cylinder. The volume of water in the container was determined by taking the difference in weight of the empty and water filled measuring cylinder. The bulk density was determined using the equation below. 


$$
\text { bulkdensity }=\frac{\mathcal{W}_{2}-w_{1}}{v}
$$

where:

$w_{1}=$ weight of empty measuring cylinder.

$w_{2}=$ weight of cylinder filled with sample.

$v=$ volume of cylinder.

\section{Effect of the Initial Concentration of Adsorption Isotherm}

The equilibrium sorption of the $\mathrm{Mn}^{2+}$ (from $4 \% \mathrm{HNO}_{3}$ solution, ICP-OES \& ICP-MS standard, SCP Science) was carried out by contacting $5.0 \mathrm{~g}$ of the HFO-resins with 250 $\mathrm{mL}$ of the solution in various concentrations in the range from $10-200 \mathrm{mg} \cdot \mathrm{L}^{-1}$ in $500 \mathrm{~mL}$ Duran conical flasks intermittently for 120 minutes on orbital shaker. The mixture was filtered and analyzed using Optimal Emission Spectrometer with inductively coupled plasma (ICP-OES; Perkin Elmer, Optima 8000). The amount of adsorbed $\left(\mathrm{mg} \cdot \mathrm{g}^{-1}\right)$ was calculated using the formulae reported by Vanderborght and Van Griekemn [9]:

$$
q_{e}=\frac{v\left(C_{0}-C_{e}\right)}{w}
$$

where:

$q_{e}=$ the amount of solute adsorbed from the solution.

$v=$ volume of the adsorbate.

$C_{0}=$ the concentration before adsorption.

$C_{e}=$ the concentration after adsorption.

$w=$ the weight in gram of the adsorbent.

The data was fitted into following isotherms: Freumdlich, Langmuir, Temkin and Dubinin-Radushkevich. The removal efficiency was determined by computing the percentage sorption using the formulae in (3).

$$
\text { Adsortion } \%=\frac{C_{0}-C_{e}}{C_{0}} \times 100
$$

\section{The Effect of Solution $p H$}

The effect of $\mathrm{pH}$ on the removal of $\mathrm{Mn}^{2+}$ using HFOs-resin was studied by varying the $\mathrm{pH}$ of the metal ion solution from 1 to 10 . The solution $\mathrm{pH}$ was adjusted by phosphate buffer and $0.1 \mathrm{~mol} \cdot \mathrm{L}^{-1} \mathrm{HCl}$ or $\mathrm{NaCl}$ solutions. A mass of $0.05 \mathrm{~g}$ of adsorbent was added to $10 \mathrm{~mL}$ of the solution containing the metal ions with an initial concentration of $200 \mathrm{mg} \cdot \mathrm{L}^{-1}$ and was the stirred with $150 \mathrm{rpm}$ agitation for $7 \mathrm{~h}$. The temperature of the solution was kept constant at $303 \mathrm{~K}$ [1]. The residual concentration of the ion was determined as explained earlier.

\section{E. The Effect of Adsorption Kinetics}

A set of experiments was conducted for studies of adsorption kinetics by placing $0.05 \mathrm{~g}$ adsorbent into $10 \mathrm{~mL}$ of solution containing $\mathrm{Mn}^{2+}$ with an initial concentration of 200 $\mathrm{mg} \cdot \mathrm{L}^{-1}$. The experiment was performed at $\mathrm{pH}=2.0$ and temperature of $303 \mathrm{~K}$. The concentration of the metal ion was periodically measure within $10-120 \mathrm{~min}$ of the experiment [10].

\section{F. The Effect of Adsorption Thermodynamic}

The effect of temperature on the adsorption of $\mathrm{Mn}^{2+}$ was investigated in order to calculate the thermodynamic parameter; $0.05 \mathrm{~g}$ of adsorbent was mixed with $10 \mathrm{~mL}$ of 200 $\mathrm{mg} \cdot \mathrm{L}^{-1}$ metal ion solutions at a range of temperature from 303-333 K [11].

\section{RESUlTS AND DISCUSSION}

\section{A. Characterization of HFOs-resin}

The hybrid sorbent HFOs-resin retained the spherical geometry and developed a deep brown color after being loaded with ferric oxide. The content of HFO loaded within the cation exchange resin was about $12.3 \%$ in Fe mass (Table I).

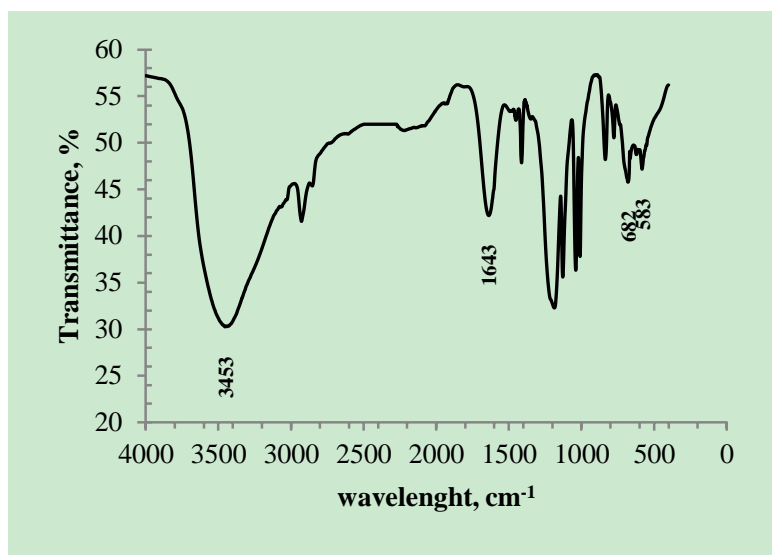

Fig. 1. FTIR chromatogram for HFOs-resin.

The FTIR spectra of HFO showed two major adsorption peaks (Fig. 1). The peak at $3453 \mathrm{~cm}^{-1}$ is for the stretching vibration of lattice water and hydroxyl group, while that located at $1643 \mathrm{~cm}^{-1}$ is for $-\mathrm{OH}$ bending vibration of adsorbed water molecules. The spectra also showed significant band of metal at 682 and $583 \mathrm{~cm}^{-1}$ for $\mathrm{Fe}^{3+}$ adsorption.

TABLE I: SOME PROPERTIES OF THE CATION EXCHANGER (KASTEL ${ }^{\circledR}$ C300L) AND HFOS-RESIN

\begin{tabular}{lll}
\cline { 2 - 3 } & \multicolumn{2}{c}{ Sorbent } \\
\cline { 2 - 3 } & Kastel $^{\circledR}$ C300L & HFOs-resin \\
\hline Matrix structure & Polystyrene & Polystyrene \\
Functional groups & $\mathrm{R}-\mathrm{SO}_{3} \mathrm{Na}$ & $\mathrm{R}-\mathrm{SO}_{3} \mathrm{Na} ; \mathrm{HFO}$ \\
BET surface area $\left(\mathrm{m}^{2} \cdot \mathrm{mg}^{-1}\right)$ & 22.7 & 29.4 \\
Average pore diameter $(\mathrm{nm})$ & 30.8 & 21.7 \\
Apparent density $\left(\mathrm{g} \cdot \mathrm{m} \cdot \mathrm{cm}^{-3}\right)$ & 0.46 & 0.62 \\
HFO content $(\mathrm{Fe}$ mass $\%)$ & 0 & 12.3 \\
\hline
\end{tabular}

\section{B. Adsorption Isotherms of Mn (II) onto HFOs-Resins}

The equilibrium adsorption of the $\mathrm{Mn}^{2+}$ was carried out as mentioned earlier. The mixture was sampled every 5 minutes to be analyzed for metal ion concentration using ICP-OES. The data was fitted into following isotherms: Freundlich, Langmuir, Temkin and Dubinin-Radushkevich.

1) Freundlich adsorption isotherm is commonly used to describe the adsorption characteristics for the heterogeneous surface. These data is often fitted with the following empirical equation proposed by Freundlich [10]:

$$
q_{e}=K_{f} C_{e}^{1 / n}
$$

where:

$K_{f}=$ Freundlich isotherm constant $\left(\mathrm{mg} \cdot \mathrm{g}^{-1}\right)$.

$n=$ adsorption intensity.

$\mathrm{C}_{\mathrm{e}}=$ the equilibrium concentration of adsorbate $\left(\mathrm{mg} \cdot \mathrm{L}^{-1}\right)$

$q_{e}=$ the amount of metal adsorbed per gram of the adsorbent at equilibrium $\left(\mathrm{mg} \cdot \mathrm{g}^{-1}\right)$. 
Linearized form of the equation (4) can be written as:

$$
\log q_{e}=\log K_{f}+\frac{1}{n} \log C_{e}
$$

The constant $K_{f}$ is an approximate indicator of adsorption capacity, while $1 / n$ is a function of the strength of adsorption in the adsorption process. If $n=1$, then the partition between the two phases are independent of the concentration. If value of $1 / n$ is below one, it indicates a normal adsorption. On the other hand, $1 / n$ being above one indicates cooperative adsorption. The function has an asymptotic maximum as the concentration is increased. As the temperature is increased, the constants $K_{f}$ and $n$ change to reflect the empirical observation that the quantity adsorbed rises more slowly and higher concentration is required to saturate the surface. However, $K_{f}$ and $n$ are characteristic parameters of the sorbent-sorbate system, which must be determined by data fitting. Linear regression is generally used to determine the parameters of kinetic and isotherm models. Specifically, the linear least-square method and the linearly transformed equation have been widely applied to correlate sorption data where $1 / n$ is heterogeneity parameter. The smaller $1 / n$ becomes, the greater the expected heterogeneity is. This expression can be reduced to a linear adsorption isotherm when $1 / n=1$. If $n$ lies between one and ten, this indicates a favorable sorption process [9-10]. The value of $1 / n=0.148$ while $n=6.757$ indicating that the sorption of $\mathrm{Mn}^{2+}$ onto HFO-resin is favorable and the $R^{2}$ value is 0.9739 proving that the sorption data is fitted well to Freundlich isotherm model.

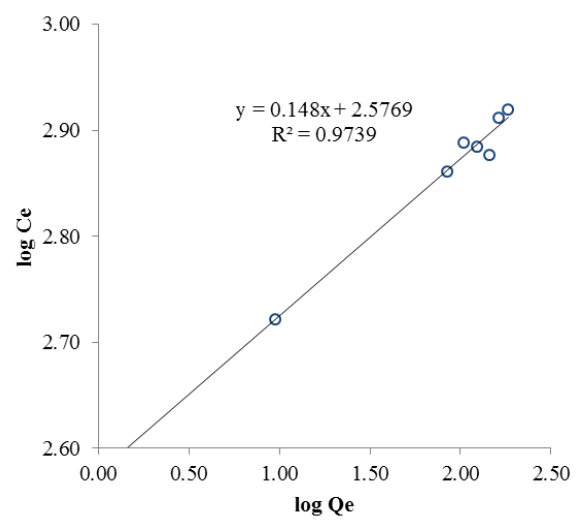

Fig. 2. Freundlich adsorption isotherm.

2) Langmuir adsorption isotherm model describes quantitatively the formation of a formation of a monolayer adsorbate on the outer surface of the adsorbent, after which no further adsorption takes place. Thereby, the Langmuir represents the equilibrium distribution of metal ions between the solid and liquid phases. The Langmuir isotherm is valid for monolayer adsorption onto a surface containing a finite number of identical sites. The model assumes uniform energy of adsorption onto the surface and no transmigration of adsorbate in the plane of the surface. Based upon these assumptions, Langmuir represented the following equation [10]:

$$
q_{e}=\frac{q_{m} K_{L} C_{e}}{1+K_{L} C_{e}}
$$

Langmuir adsorption parameters can be determined by transforming the Langmuir (6) into linear form.

$$
\frac{1}{q_{e}}=\frac{1}{q_{m}}+\frac{1}{q_{m} K_{L} C_{e}}
$$

where:

$C_{e}=$ the equilibrium concentration of adsorbate $\left(\mathrm{mg} \cdot \mathrm{L}^{-1}\right)$.

$q_{e}=$ the amount of metal adsorbed per gram of the adsorbent at equilibrium $\left(\mathrm{mg} \cdot \mathrm{g}^{-1}\right)$.

$q_{m}=$ maximum monolayer coverage capacity $\left(\mathrm{mg} \cdot \mathrm{g}^{-1}\right)$.

$K_{L}=$ Langmuir isotherm constant $\left(\mathrm{L} \cdot \mathrm{mg}^{-1}\right)$.

The value of $q_{\max }$ and $K_{L}$ were computed from the slope and intercept of the Langmuir plot of $1 / q_{e}$ versus $1 / C_{e}$. The essential features of the Langmuir isotherm may be expressed in terms of equilibrium parameter $R_{L}$, which is a dimensionless constant referred to as separation factor or equilibrium parameter.

$$
R_{L}=\frac{1}{1+\left(1+K_{L} C_{0}\right)}
$$

where:

$C_{0}=$ initial concentration

$K_{L}=$ the constant related to the energy of adsorption (Langmuir Constant).

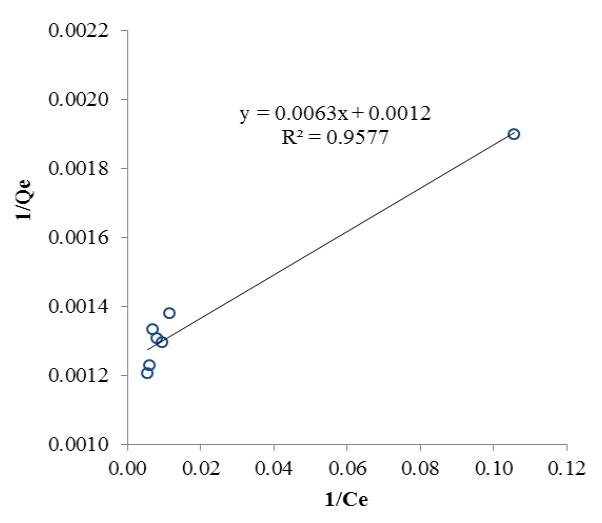

Fig. 3. Langmuir adsorption isotherm.

$R_{L}$ value indicates the adsorption nature to be either unfavorable if $R_{L}>1$, linear if $R_{L}=1$, favorable if $0<R_{L}<1$ and irreversible if $R_{L}=0$ [10]. From the result, $R_{L}$ is greater than 0 but it is less than 1 indicating that the Langmuir isotherm is favorable. The maximum monolayer coverage capacity $\left(q_{m}\right)$ from the Langmuir isotherm model was determined to be $830.50 \mathrm{mg} \cdot \mathrm{g}^{-1}, K_{L}$ (Langmuir isotherm constant) is $0.0015 \mathrm{~L} \cdot \mathrm{mg}^{-1}, R_{L}$ (the separation factor) is 0.871 indicating that the equilibrium sorption was favorable and the $R^{2}$ value is 0.9577 .

3) Temkin adsorption isotherm model contains a factor that explicitly taking into the account of adsorbent-adsorbate interactions. By ignoring the extremely low and large value of concentrations, the model assumes that heat of adsorption (function of temperature) of all molecules in the layer would decrease linearly rather than in logarithmic manner with the coverage. As implied in the equation, its derivation is characterized by a uniform distribution of binding energy (up to some maximum binding energy). The fitting was carried out by plotting the quantity sorbed $q_{e}$ against $\ln C_{e}$. The constants were determined from the slope and the intercept. The model is given by the following equation [1]: 


$$
\begin{gathered}
q_{e}=\frac{R T}{b_{T}} \ln \left(A_{T} C_{e}\right) \\
q_{e}=\frac{R T}{b_{T}} \ln A_{T}+\left(\frac{R T}{b_{T}}\right) \ln C_{e} \\
B=\frac{R T}{b_{T}} \\
q_{e}=B \ln A_{T}+B \ln C_{e}
\end{gathered}
$$

where:

$$
\begin{aligned}
A_{T}= & \text { Temkin isotherm equilibrium binding constant } \\
& \left(\mathrm{L} \cdot \mathrm{g}^{-1}\right) \\
b_{T}= & \text { Temkin isotherm constant } \\
R= & \text { Universal gas constant }\left(8.314 \mathrm{~J} \cdot \mathrm{mol}^{-1} \cdot \mathrm{K}^{-1}\right) \\
T= & \text { Temperature at } 298 \mathrm{~K} . \\
B= & \text { Constant related to heat of sorption }\left(\mathrm{J} \cdot \mathrm{mol}^{-1}\right)
\end{aligned}
$$

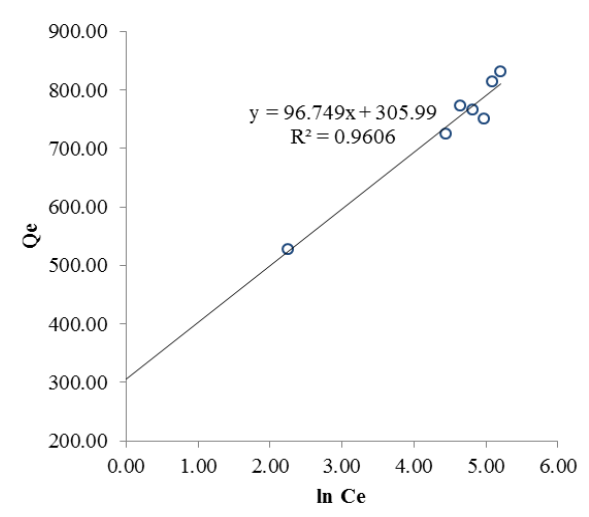

Fig. 4. Temkin adsorption isotherm.

From the Temkin plot shown in fig. 4, the following values were estimated: $A_{T}=0.484 \mathrm{~L} \cdot \mathrm{g}^{-1}, B=96.749 \mathrm{~J} \cdot \mathrm{mol}^{-1}$ which is an indication of a physical adsorption and the $R^{2}=0.9606$.

4) Dubinin-Radushkevich isotherm model is generally applied to express the adsorption mechanism with a Gaussian energy distribution onto a heterogeneous surface. The model is often successfully fitted to data with high solute activities and the intermediate range of concentration [9].

$$
\begin{gathered}
q_{e}=\left(q_{m}\right) \exp \left(-K_{a d} \varepsilon^{2}\right) \\
\ln q_{e}=\ln \left(q_{m}\right)-\left(K_{a d} \varepsilon^{2}\right)
\end{gathered}
$$

where:

$$
\begin{aligned}
q_{e}= & \begin{array}{l}
\text { amount of adsorbate in the adsorbent at } \\
\text { equilibrium }\left(\mathrm{mg} \cdot \mathrm{g}^{-1}\right) .
\end{array} \\
q_{m}= & \begin{array}{l}
\text { theoretical isotherm saturation capacity } \\
\left(\mathrm{mg} \cdot \mathrm{g}^{-1}\right) .
\end{array} \\
K_{a d}= & \begin{array}{l}
\text { Dubinin-Radushkevich isotherm constant } \\
\left(\mathrm{mol}^{2} \cdot \mathrm{kJ}^{-2}\right) .
\end{array} \\
\varepsilon= & \text { Dubinin-Radushkevich isotherm constant. }
\end{aligned}
$$

The approach was usually applied to distinguish the physical and chemical adsorption of metal ions with its mean free energy, $E$, per molecule of adsorbent (for removing a molecule from its location in the sorption space to the infinity), which can be computed by the relationship:

$$
E=\left[\frac{1}{\sqrt{2 B_{D R}}}\right]
$$

where $B_{D R}$ is denoted as the isotherm constant. Meanwhile, the parameter $\varepsilon$ can be calculated as:

$$
\varepsilon=R T \ln \left[1+\frac{1}{C_{e}}\right]
$$

where :

$$
\begin{aligned}
& R=\text { the gas constant }\left(8.314 \mathrm{~J} \cdot \mathrm{mol}^{-1} \cdot \mathrm{K}^{-1}\right) . \\
& T=\text { absolute temperature }(\mathrm{K}) . \\
& C_{e}=\text { adsorbate equilibrium concentration }\left(\mathrm{mg} \cdot \mathrm{L}^{-1}\right)
\end{aligned}
$$

One of the unique features of the Dubinin-Radushkevich isotherm model lies on the fact that it is temperature-dependent. When adsorption data from different temperatures are plotted as a function of logarithm of amount adsorbed ( $\ln q_{e}$ ) and $\varepsilon^{2}$, which is the square of potential energy, all suitable data will lie on the same curve, called the characteristic curve. The equation (13) can be linearized to equation (14) which is used in the plot of DRK graph in fig. 5. The constant such as $q_{m}$ and $K_{a d}$ were determined from the appropriate plot using equation (14). From the linear plot of DRK model, $q_{m}$ was determined to be $53.774 \mathrm{mg} \cdot \mathrm{g}^{-1}$, the mean free energy, $E=288.675 \mathrm{~J} \cdot \mathrm{mol}^{-1}$ indicating a physio-sorption process and the $R^{2}=0.9141$ was lower than of that of the Temkin model.

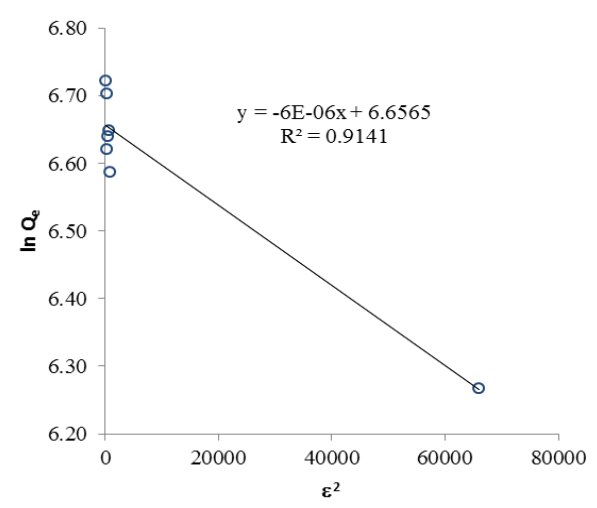

Fig. 5. Dubinin - Radushkevich adsorption isotherm.

\section{The Effect of Solution}

The Mn (II) ion uptake onto the HFOs-resin were extremely dependent on the initial $\mathrm{pH}$ of the solution because the $\mathrm{pH}$ affects the surface charge of the adsorbent, the degree of ionization of the surface groups and the nature of the adsorbing ions [2]. The results showed that the adsorption capacity of metal ions was low at low $\mathrm{pH}$, which is attributed to the fact that the high concentration and high mobility of $\mathrm{H}^{+}$ ions in the solution favors its adsorption onto the surface rather than the adsorption of $\mathrm{Mn}^{2+}$. The adsorption capacity of the HFOs-resin increases with increasing $\mathrm{pH}$ from 2 to 6 for the metal ions. The adsorption experiments could not be performed at $\mathrm{pH}>6$ because $\mathrm{Mn}$ (II) ion begin to precipitate as $\mathrm{Mn}(\mathrm{OH})_{2}$. Hence $\mathrm{pH}$ of 6 was used as the optimum $\mathrm{pH}$ throughout this study.

\section{The Effect of Initial Metal Ion Concentration}

The increase in initial Mn (II) ion concentration decreased the percentage adsorption from $97.39 \%$ to $91.41 \%$, which could be due to the limited available adsorption sites. No significant change in adsorption behavior of the HFOs-resin was observed when ion concentration was changed. 


\section{E. The Effect of Adsorption Kinetic}

Adsorption is a time dependent process. In this section, our main objective is to study the effect of pre-equilibrium contact time in order to better comprehend the adsorption kinetics of heavy metal ions onto the HFOs-resin. It was found that the amount of adsorbed ions increased rapidly in the first $25 \mathrm{~min}$, which indicates that there were enough adsorption sites for the ions to be accommodated. Then, the process slows down as the adsorption sites became gradually saturated. The adsorption equilibrium was reached at about $120 \mathrm{~min}$. Also, the adsorption of metal ions increased with agitation time, perhaps due to a decrease in mass transfer resistance in the bulk solution and an increase in the kinetic energy of the hydrated ions. The kinetics of adsorption is one of the most important aspects defining the efficiency of adsorption and also provides important information about of the rate at which the pollutant is removed from the wastewater for better design batch adsorption systems [7]. In this study, the experimental data were analyzed using a number of kinetic models in order to investigate the mechanism of heavy metal ion adsorption onto the adsorbent. The potential rate-controlling steps are transport of the ion to the surface and surface adsorption itself.

\section{F. The Effect of Temperature}

In order to investigate the effect of temperature on the adsorption capacity of Mn (II) onto the HFOs-resin, it is observed that adsorption capacity increases with increasing temperature in the range $303-333 \mathrm{~K}$, demonstrating that the process of adsorption is endothermic. This increase can be due to the increased mobility of metal ions and to their tendency to adsorb from the solution to the surface of the adsorbent as well as due to a greater activity of binding sites as the temperature is increased [10].

\section{CONCLUSIONS}

In this paper, HFOs-resin were prepared by using Kastel ${ }^{\circledR}$ $\mathrm{C} 300 \mathrm{~L}$ resin as the starting material and applied as an adsorbent. Adsorption experiments have shown that the HFOs-resin has high adsorption capacity and can be used as a sorbent for the removal of Mn (II) ion in aqueous solution. The maximum adsorption capacity of the HFOs-resin was $111.925 \mathrm{mg} \cdot \mathrm{g}^{-1}$. The pseudo-second order kinetic model was applied to the experimental data, confirming that sorption was chemically controlled and followed the intra-particle diffusion model. However, intra particle diffusion was not the sole rate-controlling step. The isotherm adsorption data were well fitted by the Freundlich model. It gave the highest $\mathrm{R}^{2}$ value, the sorption intensity which indicates favorable sorption and the correlation value were 6.757 and 0.9739 respectively. Also from Langmuir isotherm model, the maximum monolayer coverage was determined to be 830.50 $\mathrm{mg} \cdot \mathrm{g}^{-1}$, the separation factor indicating a favorable sorption experiment 0.871 . The heat of sorption process was estimated from Temkin isotherm model to be $96.749 \mathrm{~J} \cdot \mathrm{mol}^{-1}$ and the mean free energy was estimates from Dubinin-Radushkevich isotherm model to be $288.675 \mathrm{~J} \cdot \mathrm{mol}^{-1}$. Based on the thermodynamic parameters $\left(\Delta \mathrm{G}^{\circ}, \Delta \mathrm{H}^{\circ}\right.$ and $\left.\Delta \mathrm{S}^{\circ}\right)$, it was found that the adsorption process was spontaneous and endothermic over the temperature range considered.

\section{ACKNOWLEDGMENT}

The authors are thankful to Scientific and Technological Research Equipment Centre, Chulalongkorn University for equipping the analyses and Department of Chemistry, Faculty of Science and Technology, Thammasat University for core research work where this research work was carried out.

\section{REFERENCES}

[1] B. Pan, H. Qiu, B. Pan, G. Nie, L. Xiao, L. Lv, W. Zhang, Q. Zhang, and S. Zhang, "Highly efficient removal of heavy metals by olymer-supported nanosized hydrated Fe(III) oxides: Behavior and XPS study," Water Research, vol.44, pp. 815-824, Oct. 2010.

[2] N. N. Nassar, "Rapid removal and recovery of $\mathrm{Pb}$ (II) from wastewater by magnetic nanoadsorbents," J. of Hazardous Material, vol. 184, pp. 538-546, August 2010.

[3] S. Mandal, T. Padhi, and R. K. Patel, "Studies on the removal of arsenic (III) from water by a novel hybrid material," J. of Hazardous Material, vol. 192, pp. 899-908, June 2011

[4] Q. Su, B. Pan, S. Wan, W. Zhang, and L. Lv, "Use of hydrous manganese dioxide as a potential sorbent for selective removal of lead, cadmium and zinc ion from water," J. of Colloid and Interface Science, vol. 349, pp. 607-612, May 2010.

[5] S. Wan, X. Zhao, L. Lv, Q. Su, H. Gu, B. Pan, W. Zhang, Z. Lin, and J. Luan, "Selective adsorption of $\mathrm{Cd}(\mathrm{III})$ and $\mathrm{Zn}$ (III) ions by Nano Hydrous Manganese Dioxide (HMO) - Encapsulated Cation exchanger," Ind. Eng. Chem. Res., vol. 495, pp. 7574-7579, 2010.

[6] P. Puttamraju and A. K. SenGupta, "Evidence of Tunable on - off sorption behaviors of metal oxide nanoparticles: Role of ion exchanger support," Ind. Eng. Chem. Res., vol. 45, pp. 7737-7742, 2006.

[7] Q. R. Zhang, W. Du, B. C. Pan, B. J. Pan, W. M. Zhang, Q. J. Zhang, Z.W. Xu, and Q. X. Zhang, "A comparative study on $\mathrm{Pb}^{2+}, \mathrm{Zn}^{2+}$ and $\mathrm{Cd}^{2+}$ sorption onto zirconium phosphate supported by a cation exchanger," J. of Hazardous Material, vol. 152, pp. 469-475, July 2007.

[8] N. Tewari, P. Vasudevan, and B. K. Guha, "Study on biosorption of $\mathrm{Cr}(\mathrm{VI})$ by Mucor hiemalis," Biochemical Engineering Journal, vol. 23, pp. 185-192, January 2005.

[9] A. O. Dada, A. P. Olalekan, A. M. Olatunya, and O. Dada, "Langmuir, Freundlich, Temkin and Dubinin - Raduskevich isotherms studies of equilium Sorption of $\mathrm{Zn}^{2+}$ unto phosphoric acid modified rich husk," OSR J. of Applied Chemistry, vol. 3, pp. 38-45, Nov.-Dec. 2012.

[10] F. Rashidi, R. S. Sarabi, Z. Ghasemi, and A. Seif, "Kinetic, equilibrium and thermodynamic studies for the removal of lead (II) and copper (II) ions from aqueous solutions by nanocrystalline $\mathrm{TiO}_{2}$," Superlattices and Microstructures, vol. 48, pp. 577-591, December 2010.

[11] B. Pan, J. Wu, B. Pan, L. Lv, W. Zhang, L. Xiao, X. Wang, X. Tao, and S. Zheng, "Development pf polymer-based nanosized hydrated ferric oxides (HFOs) for enhanced phosphate removal from waste effluents," Water Research, vol.43, pp. 4421-4429, July 2009.

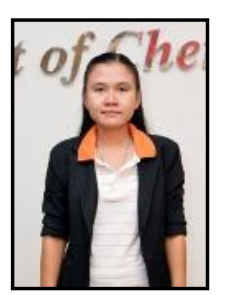

Somchintana Puttamat holds a B.Sc. degree in chemistry from Thaksin University, Songkhla Province since 2000, and now she is studying chemical engineering for master degree at Chulalongkorn University.

After graduated with a B.Sc. degree, she works as a supervisor engineer at Unocal Thailand, Ltd. for a year and she applied to become a government officer as scientist at the Department of Science Service (DSS), the Ministry of Science and Technology, Bangkok during 2002-2003. Now she works as Chemical Scientist at Department of Chemistry, Faculty of Science and Technology, Thammasat University, Thailand since 2004.

Varong Pavarajarn has graduated with a B.Eng. degree in chemical engineering from Chulalongkorn University, Bangkok, Thailand, in the 1992 and received a Ph.D. degree in chemical engineering from Oregon State University, U.S.A. in 2002. Since 2002, he has become a faculty member at the Department of Chemical Engineering, Faculty of Engineering, Chulalongkorn University, Bangkok, Thailand. Presently he holds a position as Associated Professor. 